\title{
Free to be children: Preventing child sexual abuse in Aotearoa, New Zealand
}

\author{
Robyn Salisbury (Ed.). \\ Massey University Press, Auckland, New Zealand, 2020 \\ ISBN: 9780995123007, pp.312, paperback, NZD39.99
}

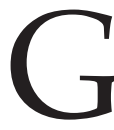
iven Aotearoa's grim statistics around child sexual abuse, this book is both timely and significant.

Robyn Salisbury, a Clinical Psychologist specialising in sex therapy, brings together a range of experts to contribute to Free to be Children. The book highlights the importance and urgency in responding to child sexual abuse and poses the poignant question: how have we let it go on for so long?

This edited book is filled with robust information, from its Foreword by Children's Commissioner Judge Andrew Becroft to the following 18 chapters.

Each chapter focuses on a different area or perspective on sexual abuse and is written by 16 contributors in total. The book incorporates writing from well-known researchers and practitioners, from a wide range of expertise, specialising in child sexual abuse. They give views and insights from the coalface (sometimes personal as well as professional).

It is very much a book about protection and not so much about healing. Key areas addressed in the book are: survivors' stories, understanding the nature of sexual abuse, children's needs, sexually harmful behaviours, underage sex work and sex trafficking, working therapeutically with those who have been abused, sexuality education and technology and the media. The second half of the book, written by people researching and working in prisons and in community treatment agencies, focuses on intervention and prevention. Free to be Children comprises new and relevant research, data on prevalence and background information on individual psyches, all of which are crucial to understand before we can look at preventing child sexual abuse.

The chapters are written by a range of experts who share their experience and give advice on how we can do better. Contributors to the book include a clinical psychologist, a police detective, a forensic paediatrician, an advocate, a chief censor, a sexual educator, experts on child sextrafficking, researchers, service managers, psychotherapists, survivors and whānau members. The knowledge shared by these specialists gives the book legitimacy, depth and informs up-to-date best practice.

The book draws together some relatively new areas (and different perspectives) for consideration in the field of child sexual abuse in this country, such as true restorative justice, child sex trafficking, and keeping children safe in this technological age.

The preface acknowledges a limitation in gaining a Pasifika perspective and, as to be expected with a book of 311 pages (and comprising the work of many authors with multiple perspectives), some chapters are easier to digest than others. Each chapter is laid out differently, some filled with stories, experiences and research, and others broken down into more manageable sections with clearly indicated recommendations. While there is no coherent thematic structure to the book, each chapter significantly adds something 
new to the reader's knowledge and understanding of child sexual abuse.

This book aims to combat taboos on talking about child sexual abuse-which it most certainly does. It encourages reflection and conversation and strongly inspires people to become informed and dare to take actions (at any level) against child sexual abuse, whether that be in a professional capacity or as a community response.

The title indicates that this book also sets out to provide guidelines or a blueprint on preventing child sexual abuse in Aotearoa and, in the final chapter, Salisbury discusses "a pathway forward". This should not be read as a stand-alone chapter and cannot be seen as a summary of previous chapters. It gives a wide range of broad and often non-specific recommendations which are important for New Zealand as a nation in preventing and responding to child sexual abuse. However, personally, I see the main focus of this book being about sharing up-to-date, holistic and relevant information about the unique Aotearoa experience and context around child sexual abuse.

I would recommend this book to a wide audience; in fact, to anyone involved with child sexual abuse, from all professionals working with children who have been sexually abused, to policy makers, students, to survivors and support people. With such breadth of information and experiences it is a must read to increase your knowledge of this complex area of abuse.

The topic is a heavy and confronting one, but each contributor writes from their heart. It is essential knowledge for all who care about our tamariki, and even those with vast experience in the field will learn something new from this book. 